\title{
ENSAYOS
}

\section{Al sur del sur: Reflexiones para una educación no sexista}

\author{
At south of the south: Reflections for an education without sexism
}

\author{
Carolina Schick Carrillo ${ }^{a}$, Daniela Zúñiga Maldonado ${ }^{b}$

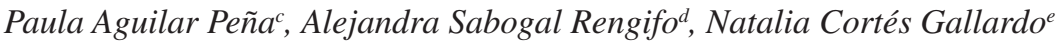

\author{
${ }^{a}$ Universidad Austral de Chile. Valdivia \\ Correo electrónico: carolina.schick@gmail.com \\ ${ }^{\mathrm{b}}$ Universidad Austral de Chile. Valdivia \\ Correo electrónico: danielazu.maldonado@gmail.com \\ c Universidad San Sebastián, sede Valdivia. Facultad de Ciencias de la Educación \\ Correo electrónico: paula.aguilar@uss.cl \\ ${ }^{\mathrm{d}}$ Universidad Austral de Chile. Valdivia \\ Correo electrónico: aleja.sabogal.renjifo@hotmail.com \\ ${ }^{\text {e } U n i v e r s i d a d ~ A u s t r a l ~ d e ~ C h i l e . ~ V a l d i v i a ~}$ \\ Correo electrónico: natalia.cortes@uach.cl
}

\section{RESUMEN}

Este artículo presenta ideas que colaboran con procesos reflexivos que la sociedad chilena está enfrentando a partir del reciente otoño feminista, que agenció demandas educativas de carácter no sexista, que tienen relación con perspectivas político-epistémicas situadas al sur del sur. Estas propuestas originadas por un círculo de mujeres estudiantes e investigadoras en educación ofrece un primer análisis que relaciona los efectos críticos del sistema patriarcal con su actual auge político-económico neoliberal en todos los niveles educativos, así como la subjetivación de las diferencias sexistas a través del uso del lenguaje y la consecuente necesidad de pensar un nuevo sistema educativo contextualizado en nuestro territorio desde la organización y participación sociocomunitaria. Se ofrece así un primer acercamiento rumbo a la consolidación de propuestas para transitar a un nuevo sistema educativo feminista para Latinoamérica.

Palabras clave: Educación no sexista, Lenguaje inclusivo, Desescolarización, Movimientos sociales en Chile.

This article presents ideas that collaborate with reflective processes that Chilean society is facing from the recent feminist autumn that brought about educational demands of a non-sexist nature, in relation to political-epistemic perspectives located south of the south. This proposal, originated in a circle of women students and researchers in education, offers a first analysis that relates the critical effects of the patriarchal system with its current neoliberal political-economic boom at all educational levels; as well as the subjectification of sexist differences through the use of language and the consequent need to think about a new educational system contextualized to our territory from the socio-community organization and participation. This offers a first approach towards the consolidation of proposals to move to a new feminist educational system for Latin America.

Key words: Non-sexist education, Inclusive language, Deschooling, social movements in Chile. 


\section{INTRODUCCIÓN}

Canta, baila, grita por amor sueña vive sin temor que los cielos esperan por ti ya tus hijas piden despertar (Araucana, Cinthia Santibáñez, Crisálida 2011).

Nuestro reciente otoño feminista, originó un cambio desde Valdivia en la dimensión de las movilizaciones: de olas pasamos a mareas, provocando reflexiones sobre una serie de delicados sucesos que han ocurrido en contextos de educación superior, ante los cuales nadie ha quedado ajena/o. En efecto, durante abril del año 2018, desde la Facultad de Filosofía y Humanidades de la Universidad Austral de Chile, se abre una "caja de Pandora" que se venía gestando hacía años: una explosión de denuncias y cuestionamientos a hombres, principalmente docentes en situaciones de poder: eventos que hasta ese entonces constituían tópicos de conversación de pasillo o de discusiones en espacios privados y seguros. Por esa fecha, se denunció la inconformidad de las estudiantes con la Institución por no hacerse cargo de los abusos sexuales que han sufrido las mujeres de todos los estamentos. Dicha situación, que se inició como un reclamo por conductas de abuso por parte de un docente en contexto laboral hacia una funcionaria, terminó generando largas reuniones, círculos de mujeres, organizaciones espontáneas y asambleas en forma de diálogos, marchas y tomas de espacios que, posteriormente, se replicaron en diversas instituciones de educación superior del resto del país.

No obstante, aquella demanda que levantó el movimiento social feminista por una "Educación no sexista", ya la veníamos escuchando fuerte y constantemente en Chile como consigna por el año 2011. Es solo que, como suele ocurrir frecuentemente en la historia de espacios de disputa social, las demandas relativas a "las mujeres" primero son reconocidas, pero después quedan relegadas a un segundo plano o simplemente son marginadas e invisibilizadas (Scott, 2008).

Para contextualizar, podemos señalar que el año 2006 con el agenciamiento de la llamada "Movilización Pingüina" se iniciaron numerosas protestas masivas que denunciaban la falta de condiciones mínimas para estudiar en Chile. Actualmente, dado el desarrollo creciente de las demandas, las movilizaciones feministas colocaron en la discusión el machismo presente en la educación. Así es como, paulatinamente, han aumentado los apellidos y complejidades de las demandas sociales para la educación de esta parte del territorio: fin a la "LOCE" (Ley Orgánica Constitucional de Enseñanza); a la "LGE" (Ley General de Educación); educación gratuita y de calidad, sin fines de lucro; educación no sexista... y aun seguimos... Sin embargo, los temas de aspectos económicos públicos, en este caso relacionados principalmente con el "lucro", terminaron ocupando la agenda en materia educativa casi por completo. Tanto es así que la movilización estudiantil chilena del año 2011 se identifica principalmente con el "lucro". Dicha invisibilización de nuestras demandas ya es una característica clásica en la historia del feminismo: aquello que nos aqueja como mujeres siempre queda a un costado, invisibilizado e instrumentalizado por otros grupos políticos. Como siempre en esta historia, las mismas mujeres son las que se debieron alzar para retomar la demanda en la agenda social, desprendiéndose de otras organizaciones institucionalizadas ya que, desde su mirada, ya se han viciado patriarcalmente. En palabras 
de Stolcke (1996), dicha lucha por la visibilización de parte de las mujeres "significó, al mismo tiempo, el desafío teórico, aunque variado de las verdades establecidas en la disciplina respecto a las mujeres en la sociedad y la historia" (Stolcke, 1996, p.336).

De esta forma, esta permanente mutilación a la diversidad se empodera sistemáticamente como una nueva problematización que no ha sido equitativa para la humanidad (Escobar, 2016) y que modela un imaginario cultural colectivo que induce a invisibilizar aun más las tenues y marginadas voces. El despojo causado por estas colonizaciones y sus consecuencias históricas que permanecen hasta el presente, no pueden ser entendidas cabalmente sin abordar la dimensión patriarcal, pues ha sido en el cuerpo de la mujer donde la humanidad aprendió a oprimir y esto se transmite a un sistema que por completo se articula para reproducir estas opresiones. Las diferentes formas de oposición ante cualquier forma de dominación tienen que iniciarse, como lo menciona Escobar (2016) por pensar e incorporar estrategias de despatriarcalización como un elemento central. Sin embargo, infundir una conciencia más aguda no solo implica negarse u oponerse a un tipo de discurso burgués, sino que además supone fomentar diferentes desplazamientos político-epistémicos con el fin de priorizar estas voces relegadas, por lo que es necesario propiciar estrategias para ir eliminando y desdibujando los límites materiales que se forman entre el privilegio y lo marginado desde la diversidad de la interseccionalidad.

Todo esto debido a que, si se entra en este juego de la jerarquía, podríamos recaer en la misma dinámica de dominación social, económica y cultural. El cuidado ante este juego recae en que este sistema, donde toda novedad intelectual o crítica termina convirtiéndose en productos del mercado, podría terminar absorbiendo la demanda, como peligrosamente está pasando en la actualidad, citando a Espinosa, Gómez, y Ochoa (2014), "en parte de una moda, en una forma de corrección política o una nueva área de especialización académica para el lucro y prestigio personal de nuevas y viejas camadas de investigadores" (2013, p.15).

“Nuestras abuelas nos dejaron el voto, nuestras madres el divorcio y nosotras les dejaremos a las que vienen el aborto" ...

(Consigna feminista)

Resulta importante señalar que el agenciamiento de estas mareas feministas ha resistido en América Latina: hemos venido tomando fuerza durante los últimos años mediante diversos sucesos que han permitido que se desencadene una oportunidad para que las mujeres se organicen y alcen la voz. La información comenzó a correr, las violencias se empezaron a desnaturalizar y las demandas históricas se volvieron nuestras, transformando las olas en maremotos de luchas. Por ello, cada 8 de marzo se ha vuelto más masivo: cada feminicidio, lejos de dejar de sorprendernos, nos moviliza aun más; cada vez que nos niegan el aborto, más pañuelos verdes se empiezan a coser y estampar mientras desplegamos gritos feministas en las marchas:

“Alerta, alerta, alerta que camina, la lucha feminista por América Latina” (Consigna feminista)

No resulta casual que las demandas que, mayormente, se han hecho visibles en el movimiento feminista latinoamericano rompieron con las delimitaciones binarias cartesianas de "lo doméstico para mujeres" y "lo público para hombres", puesto que 
esta segregación nunca fue nuestra, sino que fue incorporada desde la colonización. Los pueblos del Sur, en su compleja cosmovisión, convivían sin usar esta división como base de sus relaciones. Por lo tanto, a nuestro modo de ver, este conocimiento ancestral fue manifestado en el agenciamiento popular: las mujeres de Latinoamérica y el Caribe sentimos, pensamos y actuamos colectivamente, y en este recorrido histórico primero se sale a recuperar aquellos espacios colonialmente masculinizados, el plano político-público y, desde allí, se empiezan a re-organizar en distintas dimensiones ecológicas buscando no solo ganancias individuales sino que también pensando en seres a su cuidado y en la tierra de la que somos parte. Aquello repercute en que las movilizaciones caminan entre demandas culturales que directa e indirectamente tienen relación con el dominio de nuestras/os propias/os cuerpas/os. Como ejemplos, mencionamos esta triada de las movilizaciones históricas que transitaron desde el plano público al personal.

Primero, aparecieron las conocidas mareas por cambios al sistema democrático (derecho al voto), por conseguir derechos de propiedad y por cambiar las condiciones laborales (principalmente de obreros). Seguido, las mareas pasaron al plano familiar: desde el derecho al divorcio hasta las reivindicaciones familiares contra las violaciones a los derechos humanos de las dictaduras latinoamericanas. Ahora, las últimas mareas, tensionan planos personales: se grita contra toda violencia sobre nuestras/os cuerpas/os (aun en lucha).

En esta triada, las mujeres, después de incontables círculos, ya no solo nos proponemos avances en materias legislativas - pues entendemos que no solo se requieren cambios asistencialistas-, sino que el movimiento pide, refleja y grita que se "destruya el patriarcado", lo que en otras palabras es avanzar hasta cambiar el sistema. A lo que apuntamos es a un necesario cambio cultural, esto es, una forma distinta de relacionarnos, de administrar los roles, los poderes, las formas de co-construirnos discursivamente, la manera de amar(nos) entre personas, entre animales; en definitiva, una nueva forma de convivir como seres de la tierra.

Es precisamente sobre este proceso sociohistórico que, como grupo de mujeres y estudiantes vinculadas a la reflexión en materias de gestión y política educativa, hemos comenzado a realizarnos preguntas y cuestionamientos sobre dichas problemáticas. Estamos refiriéndonos a una educación no sexista desde el sur del sur en alusión no solo a las epistemologías relacionadas con el continente latinoamericano geográficamente situado en el sur con respecto al planeta, sino también como una forma de reivindicación del "sur austral", que es el territorio desde el cual nuestras compañeras estudiantes levantaron esta demanda feminista y, además, refiriéndonos a la existencia de un conocimiento e identidad situada que es propia del territorio. Proponemos que desde nuestro contexto socioterritorial e histórico, "tenemos el derecho de ser iguales cuando la diferencia nos inferioriza y el derecho de ser diferentes cuando la igualdad pone en peligro nuestra identidad" (Sousa, 2010, p.87).

$\mathrm{La}(\mathrm{s})$ identidad(es) de género, étnica(s), sexual(es) y otras no son homogéneas ni lineales, pues comprendemos que las realidades son diversas, pero no por ello están determinadas. Sin embargo, requieren que primordialmente sean respetadas en sus características y conocimientos ancestrales, históricos y actuales; es decir, para comprender un cambio educativo situado, es necesario re-conocernos, mirarnos en nuestras luces y oscuridades, en nuestros trans-saberes históricos y, desde allí, pensar nuestros próximos proyectos educativos, políticos, éticos, culturales y sociales para el küme mongen (buen vivir) de las comunidades. 
El planteamiento que empoderó al movimiento social del otoño feminista por una Educación no sexista dejó de manifiesto nuestras históricas opresiones, dolores y rabias acumuladas. Sin embargo, pasado el auge de descargos y caos que trajo consigo esta "caja de Pandora", hemos pensado que no es en base a la victimización ni al enjuiciamiento constante la forma en cómo avanzaremos más ágil y adecuadamente a esa transformación social, sino más bien a través de nuestras ancestrales formas de organización colectiva basadas en la confianza, paciencia y co-construcción dialógica de una nueva realidad donde (re)aprenderemos a construir relaciones que transiten hasta dejar de ser jerárquicamente opresivas. Somos conscientes de que, en este caso, el proceso responde a una condicionante de diferencias de género, pero también sabemos que no podemos dejar a un lado otras interseccionalidades que remarcan múltiples condiciones de opresión y discriminación propias de nuestro territorio: etnia, pobreza, discapacidad, derechos sociales, sustentabilidad ecológica, etc.

Así, este "Otoño Feminista" nos dejó muchas preguntas: ¿a qué nos referimos específicamente cuando hablamos de "Educación no sexista"?, ¿para qué queremos una educación sin sesgos de género?, ¿qué deberíamos hacer para impulsar una educación no sexista?

Para ello proponemos este ensayo que inicia con tres ideas centrales que no responden del todo a estos complejos cuestionamientos, pero que sí encierran nuestras primeras reflexiones colectivas acerca de las necesarias modificaciones que requiere un sistema que, desde lo agenciado por las y los estudiantes, se vuelve insuficiente para garantizar y canalizar sus demandas.

En primer lugar, contextualizaremos el estado actual del modelo educativo con sus políticas de accountability, tanto explícitas como implícitas en la cotidianidad; posteriormente, reconoceremos la importancia de los movimientos sociales como signo social que da cuenta de la enfermedad capitalista; por último, entregaremos reflexiones desescolarizantes como una de las formas de mirar el tránsito hacia una educación no sexista. Si bien aun no resolvemos por completo ninguna de las preguntas planteadas, debido a que comprendemos que es un proceso a largo plazo, presentamos aquí ciertas reflexiones desde el sur del sur, para aportar a la discusión continua en vías del cambio cultural, que abrazaremos con ansias y agradecimiento, rumbo a la transformación social que creemos permitirá mejorar la calidad de la educación para Latinoamérica.

\section{EL CONTEXTO SOCIAL: La educación como víctima de la modernidad y de la pasividad}

Los estudios nacionales e internacionales indican que entre los países de América Latina Chile es uno de los que presentan una mayor desigualdad en la distribución de ingresos (Cepal, 2010; OCDE, 2009; Solimano y Torche, 2008). Esta desigualdad encuentra su correlato en un sistema educativo altamente segmentado y estratificado. Como ejemplo, tomamos el caso de la educación superior; en ella las investigaciones señalan que, si bien en un lapso de 30 años se ha pasado de una educación elitista a una educación de acceso masivo, dicho crecimiento se ha visto acompañado por un desarrollo estratificado, en el cual son los sectores de menores recursos los que han quedado mayoritariamente excluidos de las instituciones por su alta selectividad (Bellei, Poblete, Sepúlveda, Orellana y Abarca, 2012). Así el caso de las universidades selectivas en cuanto a las prácticas que reproducen las inequidades del sistema escolar, como consecuencia no solo arrastran desigualdades 
en las distintas etapas del tránsito por la educación superior (acceso, permanencia, egreso e inserción laboral posterior), sino que la riqueza de la experiencia educativa de las y los estudiantes pertenecientes a los distintos segmentos del sistema se ve restringida al no tener estos oportunidades de interactuar con pares de realidades socioculturales diferentes.

Las investigaciones realizadas durante la última década demuestran que, mientras la educación focalizada en grupos homogéneos reproduce las inequidades sociales existentes, las experiencias educativas en contextos de diversidad están positivamente relacionadas con el desarrollo cognitivo, las actitudes, el comportamiento cívico y sirven como estimulantes para una disposición general al pensamiento complejo y actitudes socialmente responsables (Bowman, 2010, 2011; Sebastián, 2007; Bowman, N. \& Brandenberger, J., 2012). En este contexto, durante los últimos años ha cobrado relevancia el debate y la investigación nacional e internacional en torno a alternativas orientadas a revertir la desigualdad en la educación. Las recomendaciones de organismos internacionales y la presión generada por las movilizaciones sociales en el último decenio (OCDE, 2009) fueron configurando un escenario propicio para que en los sucesivos gobiernos se haya ido relevando en Chile el tema de la equidad en la Educación, lo que se ha traducido en el diseño e implementación de programas concretos como la prueba de ingreso a la educación superior complementarios o alternativos a la Prueba de Selección Universitaria (PSU).

De esta forma, lo anterior supone un compromiso no solo con la ampliación del acceso para estudiantes "meritorias/os" que aspiran a ser parte de la universidad y que provienen de distintas realidades sociales (Pérez, 2011), sino también con la permanencia, el egreso $\mathrm{y}$ un proceso respetuoso de la calidad de vida para toda/o quien aspira a ser y formarse como "estudiante". Actualmente el sistema responde a una lógica binarista y competitiva, en términos de éxito/fracaso, que endulza y enaltece la figura eufemística del "mérito" y el "esfuerzo" en condiciones que, estructuralmente, resultan ser violentamente adversas para determinadas clases sociales y comunidades marginadas. Por ello, creemos que es necesario hacerse cargo de la complejidad del problema y eliminar el carácter mercantil y antidemocrático que emana de la educación neoliberal presente en nuestro país.

Se ha observado que la exclusión en educación genera un círculo vicioso que afecta negativamente a toda la sociedad y a su desarrollo económico, tal como lo ha indicado la OCDE en sus distintos informes al respecto, el Banco Mundial, la UNESCO y el PNUD, entre otros organismos que se han ocupado del tema. Del mismo modo, en países reconocidos por sus avances en áreas educativas (como Nueva Zelanda, Canadá, Finlandia, España, entre otros) se ha observado que la inclusión genera un círculo virtuoso que afecta positivamente a toda la sociedad: el consenso apunta a que una educación de calidad en los distintos niveles genera expectativas y posibilidades de elegir la formación profesional o técnica; si, a su vez, se incorporan los apoyos necesarios cuando son requeridos y las oportunidades de acceso especial cuando corresponde y, por sobre todo, si se pone a las personas al centro del proceso. Como consecuencia, ello aporta a la construcción de sociedades más inclusivas y sistemas más justos, equitativos y de calidad.

En este sentido, el llamado de los organismos internacionales a las universidades es a fortalecer la equidad en un contexto de inequidad social; aportar a la inclusión y el aprendizaje efectivo de grupos y personas excluidas a través de políticas educativas integrales; reconocer el valor de la diversidad en educación superior en la calidad de los procesos de aprendizaje, el desarrollo del conocimiento; y valorar la diversidad como contexto para la formación ciudadana en pro de la democracia y la paz. 
Sin embargo, como señala Bauman $(2012 ; 2007)$ todas las medidas emprendidas en nombre del "rescate de la economía" se convierten (como tocadas por una varita mágica) en medidas que sirven para "enriquecer a los ricos y empobrecer a los pobres"; situación que se observa también en la educación, debido a que la barrera de la desigualdad ha sido muy compleja de cruzar. En ese sentido, las universidades y el Ministerio de Educación de Chile efectivamente han creado programas que aportan a una educación inclusiva con foco en "los más desfavorecidos", pero ¿quiénes realmente son "los desfavorecidos"?, ¿estudiantes que por motivos económicos no pueden continuar con sus estudios o aquellos que teniéndolo todo desechan toda oportunidad según mejor le convenga la siguiente oportunidad?

Podemos relacionar lo anterior con el hecho de que, durante los últimos años, hemos sido testigos de diferentes cambios e incidencias en América Latina, pues constantemente se viene redefiniendo y organizando socio-políticamente nuestro territorio; pero, a su vez, resistimos ante una sociedad que se desarrolla mayormente en función de las relaciones productivas constitutivas de neoliberalismo mediante un adiestramiento político que ejerce una violencia epistemológica sobre la multi e interculturalidad existente. En efecto, la ideología predominante no solo desdeña la lucha de la esfera pública para las propuestas sociales e investigaciones por los derechos humanos, el racismo, el especismo, el sexismo y otras interseccionalidades, sino que lo sustituye por un estado político liberal y "democrático" representativo (no necesariamente vinculante) que nos lleva a encontrarnos en tiempos variables y constantemente alienantes. Es decir, en tiempos en los que intentan hacernos creer que somos poseedores/as de nuestra libertad, en realidad nos encontramos con una libertad imaginaria e impuesta que nos impide actuar y elegir entre diferentes posibilidades pues opera como un espejismo donde solo tenemos una única opción: aquella ofrecida por el capitalismo cultural (Žižek, 2011). Nos encontramos en una época en que socialmente se valora la adquisición de productos mercantilizados como una forma de medir y definir nuestras identidades; adoptando, de esa manera, una vida desprovista de realidad (Žižek 2005, en Fernández, 2009, p.9) en la cual el mercado capitalista extiende el espejismo al generar y ofrecer productos desnaturalizados como café sin cafeína, cerveza sin alcohol, sexo virtual sin amor o universidades sin creación de conocimientos (Fuentes, H., 2013), de modo tal que "las coordenadas del deseo son proporcionadas en un contexto que enseña a desear" (Žižek, 1992 en González, 2017, p.18).

La generación actual se enfrenta a un mundo volátil, una realidad social muy diferente a aquella en la que vivieron sus padres. Por ejemplo, el título universitario promete trabajos atractivos; pero, siguiendo a Bauman (2012), la promoción social a través de la educación ya no es tal y la educación es un medio por el cual las personas recuperan el espacio, los diálogos y los derechos, pues un/a ciudadano/a que no sepa de las circunstancias políticas y sociales en las que vive difícilmente podrá direccionar su futuro ni el de sus cercanos/as.

Como es sabido, la educación está fuertemente presionada por lo utilitario, por lo eficiente y eficaz que pueda ser para lo político y los intereses corporativos. Un ejemplo de ello lo constituyen los establecimientos educacionales chilenos, cuyo sistema replica condiciones de inequidad, clasismo y de deficiente calidad. En efecto, las últimas pruebas estandarizadas aplicadas en Chile, como el Sistema de Medición de la Calidad de la Educación (SIMCE) y la Prueba de Selección Universitaria (PSU), permiten entrever que cada día se abandona más la noción de conocimiento útil para la vida y se cambia por uno desechable cuya validez es pasajera y efímera. De este modo, el saber y el conocer se 
presuponen como exclusivos de las funciones cognitivas, pero igualmente olvidan y por sobre todo obvian e invisibilizan otras esferas de importancia para el desarrollo humano, social y planetario: Diversidad de sentipensares (Fals Borda, 2009) corporales, espirituales, laicos, ancestrales y colaborativos, entre múltiples otros. Al parecer, la educación de antaño, los conocimientos sólidos y el discurso pedagógico, pasaron a un segundo plano.

En esta sociedad que día a día hace metamorfosis, todo y nada puede ocurrir con certeza absoluta: "hoy el conocimiento es una mercancía; al menos se ha fundido en el molde de la mercancía y se incita a seguir formándose en concordancia con el modelo de la mercancía” (Bauman, 2012, p. 30). Así, frente a evidencias como estas, nos preguntamos ¿cuál es la justificación de que el Ministerio de Educación chileno le "saque el polvo" a los viejos libros y pruebe modelos que ya otros países han desechado? Como ya es sabido, el Gobierno Militar, en años de dictadura, desmanteló el sistema de educación pública chileno al privatizar y mercantilizar derechos sociales al "mejor postor", defendiendo paradigmas inequitativos que promovieron aun más las diferencias entre ricos y pobres. Hoy, a treinta años del supuesto "regreso de la democracia" continuamos en el mismo escenario. Frente a esto debemos re-preguntarnos cuantas veces sea necesario: ¿qué cambios se han hecho para entregar a nuestra ciudadanía una educación de calidad?

A nuestro juicio, las actuales políticas en educación se mueven entre acciones asistencialistas, caritativas y cortoplacistas que no han generado transformaciones efectivas para disminuir las brechas de inequidad de las distintas clases sociales. Esto constituye una deshonra para las familias trabajadoras que buscan la movilidad social a través de la educación pues la educación no es un bono, no es un estipendio, es un derecho que le corresponde a todo ciudadano/a y, por tanto, resulta sumamente importante comenzar a repensar para poner la mirada en la calidad ofrecida y terminar de una buena vez con el lucro.

Así, en un constante ir y venir de información, mixturas teóricas y opiniones (que a veces esclarecen y otras veces confunden), tomamos y encendemos la alerta que camina para remover las acciones por parte de las y los actores en educación. Creemos que este es el momento de proponer y movilizar cambios pues contamos con aquel impulso que falta para salir del "subdesarrollo" que produce la pobreza; y para entender que la educación no puede seguir esperando y que el conocimiento no puede seguir siendo "líquido" (Bauman, 2012). La ideología predominante, tanto en educación como en otras esferas, constantemente disfraza su arrogancia y poder con un sutil y permisible manto de seda, poco a poco seduce y es mediante la cortesía que invisibiliza todo aquello que impide alcanzar otros objetivos y proyectos. Hay que estar atentos/as pues el mismo sistema se defenderá, pero ante ello resulta relevante aceptar que no hacer nada frente a ello, y mantenernos en pasividad frente a estos hechos que día a día están en frente de nosotras/os, implica igualmente una posición política que es el aceptar toda relación de poder, dominación y opresión interseccional existente (Žižek, 2005 en Fernández, 2009).

\section{EL LENGUAJE COMO UN SÍMBOLO, NO UNA REALIDAD. EL MAPA, NO EL TERRITORIO: UNA REFLEXIÓN SOBRE EL USO INCLUSIVO DEL LENGUAJE}

Siguiendo los planteamientos del lingüista y semantista general Alfred Korzybski, en las siguientes líneas proponemos algunas reflexiones en relación con el carácter simbólico del lenguaje y las implicancias de postular tal afirmación. Asimismo, nos apegamos a una 
perspectiva funcional basada en el principio de que el lenguaje debe explicarse desde sus funciones esenciales, la comunicación y la interacción, dada la creencia de que son estas funciones las que modelan al propio lenguaje (Llorente, 1996) y que, aunque ya resulte reiterativo, el uso de la lengua sí trae consigo acción enunciativa pues permite generar ciertos cambios simbólicos en nuestras percepciones acerca del mundo al nombrarlo y referirnos a él.

En los territorios del Sur, desde la llegada de los gobiernos democráticos en 1990, la sociedad chilena se ha transformado en diversos aspectos y sufrido una serie de cambios políticos, sociológicos, morales y tecnológicos. Una de las modificaciones importantes parece ser la transición de una sociedad conformista, hacia una sociedad que demanda participación, vinculación e inclusión. Como indica el Informe de Desarrollo Humano en Chile del año 2009, del Programa de Desarrollo de las Naciones Unidas (PNUD), el entorno de seguridad y estabilidad que se consolidó durante los 90 provocó una importante reducción del temor a los conflictos y a la expresión de las diferencias. Sin duda un importante cambio que, de forma simultánea, alentó enormemente la expresión de las demandas sociales (Informe PNUD, 2009). Dicho movimiento social, conformado por grupos de variado tipo (estudiantes universitarios y escolares, organizaciones LGBTIQ + , movimientos indígenas, feministas, minorías políticas, entre otros) han iniciado una variada gama de demandas en los últimos años, entre las cuales el uso de un lenguaje no sexista no ha sido una excepción. Así, estos grupos organizados de forma colectiva muestran una mayor disposición a exigir nuevas prácticas sociales con el objetivo de alcanzar sus derechos y lograr cambios significativos (Aguilar, 2015).

El año 2012, tras la publicación de una polémica columna en torno al lenguaje sexista aparecida en un conocido diario español escrita por el lingüista y gramático español Ignacio Bosque, se reavivó un debate social entre los partidarios de modificar los usos comunicativos con el fin de evitar el sexismo lingüístico y aquellos que abogan por negar dichas propuestas. El lingüista español explica en dicho texto, entre otros asuntos, lo "innecesario" que resulta la duplicación del género al referirse a hombres y mujeres, argumentando que, desde la teoría gramatical y siguiendo rasgos de economía del lenguaje, sería recomendable utilizar el morfema de género masculino que por convención social trae "implícito" la generalización e inclusión de ambos géneros, pues en dichos casos resultaría redundante su duplicación. Ese año, aquel artículo generó una serie de reacciones, no obstante, el debate y estudio de las relaciones entre el uso del lenguaje e ideologías "que perpetúa la situación de desigualdad de la mujer no es reciente” (Márquez, 2013, p.7).

Desde los años 70, la lingüista norteamericana Lakoff ha aportado con importantes estudios en torno al género y lenguaje, propuestas que han dado espacio a reflexiones posteriores sobre la propia categoría de género. Entre los planteamientos iniciales, Lakoff propone que cuando las sociedades de los seres humanos confrontan ideas y realidades que son profundamente conmovedoras y perturbadoras, hacen algo unívoco y esencialmente humano: crean cultura en torno a ellas, mito, religión, arte y ciencia. De este modo, lo que se siente caótico y fuera de control se reduce a lo lícito y a aquello que es comprensible y predecible. Todo esto se visibiliza y emerge en torno al lenguaje, ya que las culturas buscan de esta forma dar sentido a la dualidad intrínseca: el lenguaje se ha enraizado poderosamente, con un pie en lo real y tangible, y el otro en el aireado mundo de la imaginación (Lakoff, 1990). Así, el lenguaje se torna poderoso pues el lenguaje es poder y se constituye en una fuerza que crea cambios y, por lo tanto, debe temerse y usarse con 
cuidado. Esta autora propone que las palabras pueden ser poderosas, pueden afectar la realidad, pese a que también pueden no hacerlo. Las palabras se vuelven poderosas porque pueden usarse como herramientas, como un martillo o un arma de fuego. Así, propone una idea central: las palabras no hacen cambios por sí mismas, sino que a través del uso de un ser humano hábil o torpe.

Las armas no matan personas, a la Asociación Nacional del Rifle le gusta decir: la gente mata gente. Por la misma razón, las palabras no cambian la realidad, las personas cambian la realidad. Pero al igual que las armas, las palabras hacen posible que las personas logren los efectos que buscan (Lakoff, 1990, p. 15).

$\mathrm{Al}$ seleccionar nuestras estrategias comunicativas, que conforman los enunciados que estructuran nuestros discursos, la libertad de decisión de la que disponemos es ciertamente relativa si consideramos la presión que ejerce el entorno social en nuestras conductas e interacciones verbales, ya que

en toda sociedad la producción del discurso está a la vez controlada, seleccionada y redistribuida por un cierto número de procedimientos que tienen por función conjurar los poderes y peligros, dominar el acontecimiento aleatorio y esquivar su pesada y temible materialidad (...) el discurso (...) las prohibiciones que recaen sobre él, revelan muy pronto, rápidamente, su vinculación con el deseo y con el poder (Foucault, 1992, pp. 5-6).

Con todo, pese a lo dirigidas que puedan estar nuestras interacciones a causa de requerimientos sociales, es innegable que realizamos elecciones léxicas, sintácticas y pragmáticas al entablar cualquier contacto lingüístico, situación que reafirma la capacidad de acción (Butler, 2018) de la que disponemos los seres humanos. Recordamos así que la lengua es en sí misma acción (Austin, 1962; Searle, 1969) y no es el nombre que damos a las cosas lo que permitiría modificar cierta parte del mundo, una parte de la realidad, sino que el acto mismo de nombrar, es decir, la fuerza ilocutiva de nuestros enunciados. Por tanto, al cambiar los usos de una lengua, lo queramos o no, "cambia al menos una porción de la realidad: aquella referida al mundo de los sonidos y los significados, a la representación simbólica y a la cosmovisión, las cuales condicionan nuestras percepciones, ideas, emociones y nuestra actuación" (Márquez, 2013,p. 8).

Del mismo modo, cuando afirmamos que el sujeto está constituido, esto solo significa que el sujeto es el resultado de algunos discursos gobernados por normas que conforman la mención inteligible de identidad. Por tanto, es importante recalcar que

el sujeto no está formado por las reglas mediante las cuales es creado, porque la significación no es un acto fundador, sino más bien un procedimiento regulado de repetición que al mismo tiempo se esconde y dicta sus reglas precisamente mediante la producción de efectos sustancializadores (Butler, 2018, p. 282).

Desde esta perspectiva, la significación tiene lugar "dentro de la órbita de la obligación de repetir; así pues, la "capacidad de acción" es estar dentro de la posibilidad de cambiar esa repetición” (Butler, 2018, p. 282). 
Queda así la reflexión en torno a la relevancia de proponer nuevos usos de tipo gramatical que permitan visibilizar dichas necesidades de inclusión social que actualmente las estructuras gramaticales del español no permiten evidenciar. Debate que hasta hace algunos años no había sido enunciado con claridad. Así, el uso de $x$, $e$, @ en el rol de morfemas de género, estructuras que permiten sacar a la luz la necesidad de expresar una mayor diversidad de géneros, constituye en sí misma una demanda inclusiva social necesaria pero que habría que tomar con cautela debido al carácter convencional que, como sabemos desde Saussure, posee el signo lingüístico, rasgo que implica que exista un consenso en relación con el significado de las estructuras lingüísticas. Dicha convención evidentemente puede sufrir modificaciones, pues indudablemente es el uso del lenguaje el que dirige su accionar. Por esta razón, está dentro de nuestra "capacidad de acción" usar dichas propuestas y cambiar el panorama lingüístico, pero ello debe partir por la forma de relacionarnos, esto es, ser inclusivos en la forma de convivir y reconocer a un otra/o más allá del uso o no de los morfemas; valorar el léxico y usos propios del español chileno, rasgos que nos hacen distintivos en el Sur. Así, dentro de unos años "el mapa” será capaz de reflejar las modificaciones que ha sufrido el territorio discursivo, simbólico y performativo frente a las exigencias inclusivas de sentirnos representados por las estructuras que articulan y conforman nuestro pensamiento.

Podemos proponer así que el feminismo constituye un movimiento social internamente poliédrico (del Valle, 2018) que progresa en relación dinámica con otras causas interseccionales en las que grupos sociales marginados pretenden convertirse en actores políticos. Por esta razón,

dada su relevancia en múltiples dimensiones del cambio social, es imperativo no limitar la discusión sobre el lenguaje inclusivo a consideraciones superficiales: ¿respetan o no las innovaciones la matriz gramatical del idioma? ¿Triunfará o no tal o cual forma? Es necesario mantener vivo el fuego de una reflexión glotopolítica para evitar la frivolización de fenómenos lingüísticos que son de hecho elementos integrales de los procesos de emancipación (del Valle, 2018, p 1).

Proponemos, siguiendo a Arcos et al. (2006) que la universidad, en su rol social y mediador en la incorporación de políticas públicas, tiene una fuerte responsabilidad social en el sentido de asumir protagonismo y liderar el proceso incorporando nuevos conceptos, "organizar procesos de análisis y reflexión, transformar las representaciones simbólicas 'tradicionales' y participar en acciones concretas de la realidad subjetiva-objetiva de identidades y relaciones de género" (2006, p.43). De esta forma, luego de un cambio cultural, el lenguaje por sí mismo irá reflejando aquella inclusividad de nuestras relaciones sociales.

\section{MOVIMIENTOS SOCIALES: LA MINGA COMO ORGANIZACIÓN SORORAL DEL SUR. TEORÍA PERFORMATIVA DE LA ASAMBLEA Y LA LUCHA POR UNA EDUCACIÓN NO SEXISTA}

Nuestro continente continúa siendo colonizado: paulatinamente se consolida un modelo político-económico de mercado que permea a los sistemas en distintos frentes y la educación con las diversas políticas de accountability (Assaél, Acuña, Contreras, Corbalán, 2014) 
no se ha quedado atrás. Razón por la cual desde las y los mismos estudiantes y diversos actores sociales, se han levantado asambleas de lucha política como un signo de alerta ante la enfermedad homogeneizante del capitalismo.

Bajo una histórica ordenación mercantil, es comprensible que el propio sistema no atienda a cómo organizarse de forma de dar cuenta a esta demanda, puesto que la solución no responderá a una línea positivista de causa-efecto, sino que a través de la aceptación de la complejidad. Por tanto, debemos estar atentas y ser cuidadosos/as puesto que, para este sistema, es posible caer en el reduccionismo predictivo-homogeneizante de los cuerpos que lo integran como método de "solución" a esta demanda. Es un método de defensa, puesto que los estudiantes están pensando complejamente, fuera del adulto-centrismo y la hiperespecialización.

El cambio temporal ha hecho que las nuevas generaciones estén pensando en presente, mirando su pasado y proyectando el futuro a la vez, con demandas performativas en formas de minga(s) con las que se encuentran resistiendo consciente e inconscientemente no solo con palabras, sino que desde sus propios cuerpos y utilizando estrategias propias de las nuevas generaciones. Un ejemplo de ello fueron las multitudinarias y creativas protestas desde los Flashmob como el "Thriller por la educación" del año 2011, hasta los pechos al aire de las protestas feministas en 2018 (Rodríguez, 2018).

La minga es una forma de organización comunitaria propia de la cultura del sur del sur que se basa en el principio de ayuda solidaria y no caritativa. Para que un sujeto se sienta bien, se debe, a su vez, estar bien en comunidad y con-vivir en Küme Möngen: ante la necesidad de una persona o grupo, la propia comunidad se empodera y organiza para colaborar haciéndose parte del requerimiento emergente (Arriagada, 2016). Es decir, se genera agenciamiento que va más allá de los asistencialismos, por lo que para un evento contextual es la comunidad la que se moviliza. Estos eventos pueden ser tiraduras de casas, reclamos por la salud digna, organización de mateadas; y, en este caso, son los círculos de mujeres los que buscan el cambio cultural. Esta forma de organización es emergente, contextualizada y no homogeneizada burocráticamente en lo institucional puesto que no es estática, es voluntaria y, en ello, en esa neguentropía dentro del caos, se mantiene el espíritu crítico de la asamblea y sus acciones performativas (Butler, 2015).

Como parte de la marea feminista, desde abril de 2018 aproximadamente, se agenció la organización de una minga al sur del sur: una marea de tomas de facultades de la Universidad Austral de Chile, Valdivia; que, posteriormente, se ramificaron hacia el resto del país en forma de movilizaciones por parte de círculos de mujeres de distintos niveles educativos (superior y secundarias). Este movimiento se ha planteado en paralelo a otras demandas feministas de Latinoamérica como el fin a los feminicidios, al acoso callejero y la legalización del aborto. Por ello, consideramos que resulta indispensable que las ciencias que estudian fenómenos educativos recojan, miren y reflexionen ante la petición popular actual por una "Educación no sexista" (Acuña y Montecino, 2014; Aguilera, 2018), no solo como un mecanismo reaccionario en respuesta a una demanda social de manera compensatoria, sino que, más bien, como la generación de momentos de indispensable reflexión dialógica, para trabajar en profundas modificaciones culturales. Para generar nuevos valores se pueden articular estas acciones al mundo educativo, puesto que son parte de nuestras formas de resistencia cotidianas y ancestrales; pero, a su vez, deben ser respetados y valorados los espacios de asambleas populares no institucionalizados que se reúnen de manera inesperada y voluntaria o involuntariamente se disuelven no por opresión, 
sino que, es en esta transitoriedad, en esta no estática forma causal de organización, donde se mantiene y desarrolla su función "crítica" (Butler, 2015).

Por ende, es necesario pensar y consolidar procesos a largo plazo pues deberemos (de) construir nuestros propios conocimientos desde el planteamiento del origen paradigmático de las ciencias y de la forma en cómo co-construyen realidades desde el universo educativo: ¿cuál es nuestro proyecto político-ideológico en la educación a nivel nacional?, ¿cómo podríamos avanzar a una educación "no sexista" bajo el mismo modelo que genera relaciones misóginas y heteronormativas?, ¿dónde se inicia el sexismo en la educación: en quienes se educan o en quienes proyectan lo que "se educa"? A nuestro parecer, en todos estos micro, meso y macro niveles, por lo que la solución a este clamor por modificaciones culturales requiere de estrategias a corto, mediano y largo plazo; no solo curriculares, no solo de manera aislada al interior de las aulas, sino que en todo el conjunto de dispositivos articulados para las materias educativas en constante diálogo con la comunidad.

¿Cuál es nuestra propuesta? De-construir y des-colonizar los cuerpos desde un conocimiento situado y territorializado, que en nuestro caso provendría desde la diversidad al sur del sur: Podemos cultivar la minga como forma de organización performativa y sororal en respeto a todo ser vivo, y no solo mirando hacia el hombre-blanco-cis-heteronormado como lo hace el sistema capitalista-patriarcal actual, sino que situar la organización política abarcando la diversidad de los cuerpos que la integran. Esto, en consecuencia, de que no se trata de la búsqueda de equidad para conseguir "cualquier igualdad", puesto que es en estos actos performativos a los que nos referimos en los cuales los mismos cuerpos aliados en luchas políticas llaman a generar nuevos valores (como por ejemplo las movilizaciones feministas actuales), pero no llaman a conseguir una "igualdad" que nos haga vivir las mismas condiciones invivibles (Butler, 2015) a las que nos ha expuesto el capitalismo, sino a que repensemos la igualdad partiendo desde la base de que somos y seguiremos siendo diversidad.

La práctica ancestral de los pueblos de Los Andes, hoy, se configura como las formas de organización de comunidades en disputa, puesto que es mucho más que la suma de esfuerzos particulares: es el tejido complejo desde los diálogos e historias en común que logran hacer que nos miremos y dialoguemos sobre cómo queremos relacionarnos y qué queremos aprender del pasado para transformar nuestra realidad eco-social. La educación sexista debe terminar, y para ello el movimiento feminista está creciendo y se está fortaleciendo, porque en comunidad y diálogo nos estamos armando contra el patriarcado.

\section{LA DESESCOLARIZACIÓN ¿UNA ALTERNATIVA PARA LA CONSTRUCCIÓN DE UNA EDUCACIÓN ANTIPATRIARCAL?}

Si para pensar en una educación antipatriarcal consideramos que es preciso la utilización de un lenguaje inclusivo y la organización mingal, también es necesario (re)considerar, cuantas veces sea necesario, los métodos de evaluación y las competencias propias tanto del aprendizaje como del currículum oculto: ¿no supondría esto pensar en una educación completamente diferente a la que concebimos hoy en día? Nuestra respuesta es sí... Incluso podemos ir más allá, sentipensando una sociedad distinta.

Como hemos mencionado anteriormente, la actual educación formal y el sistema que trae aparejado responden a una lógica mercantil que, como bien propone Illich (2011), 
repercute en que la educación como tal se vuelve en un elemento de alta demanda, producto de un proceso tecnificado, que genera dentro de sí mismo la necesidad de una educación constante, pero basada en la competencia y en la adquisición de productos mercantiles.

Comprender este proceso es fundamental, pues la lógica de consumo que esta contiene está basada en la competencia desde el imaginario impuesto del "éxito/fracaso", por lo que la educación se convierte en el sistema perfecto para la re-producción de sujetos (no agentes) que les son funcionales, puesto que sirven para producir y reproducir este modelo social. Estos elementos son de gran importancia, pues la competencia, el consumo y la producción en serie de sujetos uniformes da pie a la segregación, discriminación y a la colonización, en términos tanto macro como micro políticos. Esto porque el sistema macro permea, como un espejo, las prácticas cotidianas y, por tanto, serán el reflejo de las formas que tenemos de relacionarnos.

Illich (2011) da cuenta de la dependencia institucional que implica la escolarización. Este es un punto de gran alcance, ya que esta necesidad de adquirir mercancías y educación es en pos de una demanda que lo institucional debe cubrir. Estas lógicas también se ven a niveles micro, en nuestras relaciones y nos permiten ver cómo no es posible pensar en capitalismo sin patriarcado. De esta manera, la segregación educativa siempre tiene un ganador y varios perdedores, donde estos últimos siempre corresponden a minorías excluidas, a "cuerpos abyectos"; el género es un claro criterio de selección para la discriminación, así como la etnia, la discapacidad, la vulnerabilidad social, las orientaciones sexuales diversas y todo otro modo de exclusión social. Por tanto, las formas desde las que se evalúa y se juega en este sistema están puestas en la competencia, por lo que la "colaboración" es una categoría no aplicable, ya que no se enseña ni se promueve, a pesar de que se declara en el discurso como parte de los proyectos políticos educativos, en términos prácticos y performativos, no se le otorga un espacio central, pues responde a los modos de operar del currículum oculto como aquello que permanece camuflado, pasando por debajo desde lo no explícitamente dicho, pues desde este tipo de prácticas es desde donde se mercantiliza la educación. En ese sentido,

el currículum siempre es el resultado de una selección: de un universo más amplio de conocimiento, se elige solo una parte. Pero ¿qué parte?, de ahí que el currículum funcione como un mecanismo de poder social, puesto que otorga privilegio a un tipo de conocimiento, una identidad, por sobre otro (Tadeu da Silva, 2010 en Lillo, 2016, p. 26).

Estos claramente no son solo contenidos estandarizados; sino que, además, se encuentran permeados por los valores, formas de hacer y de ver aquello macro-político que busca, desde lo simbólico, imponer. Por ello resulta interesante retomar los alcances del curriculum oculto como lenguaje del sistema en su potencialidad performativa y, por sobre todo, cómo todo esto termina traducido en estereotipos y roles que perpetúan la desigualdad social como mecanismo de mantención de un status quo en desmedro del Küme Möngen de los cuerpos abyectos.

De esta manera, complementamos con lo propuesto por Illich (2011) y Dussel (2007) quienes dan cuenta de la necesidad de transformación que requiere una sociedad, para dejar de discriminar y segregar, pues esta propicia desde sus bases la generación de desigualdad y marginalidad. Para ello, esta transformación requiere de nuevas lógicas. Siguiendo a Dussel (2007) y de acuerdo con Žižek (2011), no debemos remodelar la habitación o crear nuevas habitaciones desde las que fingir inclusión para vivir con menos culpa sin cuestionar 
los modos y las formas, con el fin de no cambiar ni perder los privilegios, sino que es necesario derrumbar la casa y levantar espacios cooperativos, comunitarios y diversos que posibiliten las mingas de aprendizaje en todas sus acepciones, donde las ahora "minorías" tengan un espacio y una voz.

Para ello, Žižek (2012) nos invita a empezar reconociendo que nos encontramos en una época donde la competencia y la comparación social es mucho más importante que los sentimientos y los derechos de los demás, puesto que nos hallamos en una cultura capitalista enfocada en el sometimiento y la aprobación constante; lo que nos convierte en esclavos/as de una sociedad hipócrita, que mediante el optimismo caritativo barato quiere resolver los problemas mundiales. Sin embargo, para hacer cambios radicales estos no se pueden empezar "sin aceptar con valentía la plena actualización de una causa, incluido el riesgo inevitable de un desastre catastrófico" (Žižek, 2011, p. 14). Ante ello, debemos aclarar que nuestra propuesta no es aplicar didácticas cooperativas y sensorio-corporales en aula sin teoría que la fundamente, así como tampoco lo es realizar conversatorios comunitarios interminables disfrazados de constructivismo, sino intencionar espacios críticos para superar dialógicamente las opresiones del sistema patriarcal.

En ese sentido cabe preguntar ¿la desescolarización podría significar una posibilidad de cambio, esto es, de virar a una educación feminista - antipatriarcal? Tanto Žižek (2011), como Illich (2011) dan cuenta de que aun sin saber lo que significa realmente hacer un cambio, una transformación realmente revolucionaria, se debe asumir el costo de intentarlo pues, de lo contrario, el círculo vicioso continúa aun cuando los resultados puedan no ser los esperados. La lucha del feminismo, en toda su amplitud, supone formas de relacionarse justas, colaborativas y respetuosas de la otredad; y es ahí donde debemos dejar de ser sujetas y sujetos para pasar a ser agentes activos, lo que supone dejar la dependencia a la institucionalidad y hacernos cargo de nuestros procesos sociales. Un ejercicio complejo y dificultoso aun para la totalidad de quienes no conocemos otro sistema sino este, pues la escolarización como lógica dominante está encarnada incluso a nivel corporal, incluso en la concepción de salud, y es esto precisamente lo que hace del feminismo y la desescolarización un acto político pues se requiere de una ética convivencial, o convivial, como bien propone Illich, desde donde lo material esté dispuesto para el uso, como un medio para el cultivo personal y colaborativo, para el buen vivir.

Desde este punto, pensar en la desescolarización como una posibilidad educativa feminista, implica repensar el lenguaje - como constructo de realidad - y los espacios públicos, no solo como espacios de tránsito, ni potenciales espacios para la publicidad, sino como espacios desde donde se teje lo cotidiano y lo comunitario, devolviéndole el poder al encuentro desde su potencial para el aprendizaje, y así reformular lo que entendemos por ello, lo educativo y las formas de relaciones humanas: ¿cómo nos relacionamos desde el feminismo?, ¿es posible evaluar desde el feminismo?, ¿cómo generamos espacios feministas?

Responder a estas interrogantes podría resultar relativamente simple desde la generación de políticas públicas que responden al modelo actual; sin embargo, si se busca generar un cambio real, el ejercicio se complejiza por dos razones: la primera corresponde a dejar la mirada asistencialista y comprender lo institucional como un posibilitador y, en segundo lugar, cabría preguntarnos, ¿cómo podemos pensar en algo que no conocemos? Parece ser una alternativa arriesgada pues tenemos el fantasma constante de la escolarización desde la que nos entendemos y entendemos lo social, como parte de nuestra ilusión de control. 
Todo ello constituye un gran desafío desde donde es preciso una toma de conciencia de los procesos actuales, nuestras relaciones, de mirar-se/nos, así como de la forma en la cual nos articulamos y definimos como seres humanos y de la tierra. En efecto, implica una deconstrucción profunda en la cual seguramente los cambios reales no serán vistos por nosotras, sino que por quienes hayan sido educados bajo la desescolarización de la sociedad patriarcal. Pero desde el sur del sur, mirando la sororidad latinoamericana, tensionamos los cuestionamientos: ¿existen otras formas desde las cuales se haya entendido la educación? Nuestra respuesta es sí, y esto implica dejar de mirar la superficie de las olas y las mareas para sumergirnos en el vasto océano de los saberes ancestrales, tradicionales y populares, desde la cosmovisión de los distintos pueblos, pues pensar en salir de la lógica escolarizada implica volver a dar valor a los aprendizajes basados en la experiencia donde el contenido (información) y la vida no están separados: hacer, saber y conocer van de la mano, por lo que el aprendizaje experiencial implica salir de los binarismos cartesianos y entrar en la complejidad del todo, pero también de lo local, de lo situado, del poder del territorio.

En este sentido, el aprendizaje experiencial invita a la acción, a tomar valor de lo que sabemos y sentimos hacer, pero también a cultivarse desde el saber como un modo de abrir horizontes y perspectivas, desde los lugares desde los que hacemos. Acudir y revalorizar los saberes ancestrales, también implicaría comprenderlos desde el hibridaje, como un medio para la reconstrucción de espacios para lo diverso, que apunte a una sociedad donde el feminismo deje de ser una necesidad y pase a ser parte de nuestras formas de vida. Pero para ello, es indispensable la revisión y transformación de cada una de las formas desde las que hacemos y entendemos; en concreto, la forma en la que, por ejemplo, valoramos el sentir, el saber y el acceso al conocimiento pues, de esta forma, el certificado de estudios como tal dejaría de ser la vara desde la que se mide el éxito/fracaso y se enaltezcan oficios no como mano de obra barata para el sistema, sino que como parte de los roles comunitarios, como parte de la minga constante por mejorar nuestras formas de convivir. De este modo, se otorgaría una revalorización que invita a desalinearse, no solo mirando lo que se hace, sino del cómo se siente y se hace.

\section{ALGUNAS CONCLUSIONES}

“¡Ahora que estamos juntas, ahora que sí nos (leen) ven!”

(Extracto consigna feminista)

Las asambleas y el agenciamiento de los cuerpos aliados que hoy se siguen levantando para cambiar nuestra cultura parten y requieren partir en todo el contexto educativo: resulta necesario mirar(nos), conocer nuestras historias, reflexionar sobre nuestras acciones, nuestras palabras, nuestras emociones y cómo estas se reproducen en nuestros actos cotidianos y en la política a la que adscribimos o bien, a las que estamos sometidas. Nuestro otoño feminista nos permitió reflexiones profundas, fuertes y sumamente delicadas sobre el sistema educativo, en donde los principales temas a tratar iniciaron con las denuncias y abusos de poder que no eran tomados en cuenta ni mucho menos valorados como temáticas de alta importancia puesto que aun escasean los resguardos jurídicos, educativos y de salud que permitan enfrentar estas situaciones. No podemos afirmar que fue este el único hito 
detonante del caos que sale de la caja de Pandora, pero sí podemos afirmar que fue un importante espacio para empezar una nueva comunidad.

Resulta necesario reflexionar, criticar y transformar nuestro sistema educativo y dejar de mirar únicamente los aspectos económicos-mercantiles, pues la réplica de estos sucesos neoliberales permiten la marginación de diversos grupos sociales encarnados en lo que considera cuerpos abyectos por medio del sostenimiento de la inequidad, injusticia y desigualdad, lo que nos convierte en posibilitadores y cómplices pasivos de estas acciones y, por tanto, de la homogeneización, normalización y resguardo de las lógicas dominantes desde la cotidianidad, donde cada espacio diferente es susceptible de ser mutilado, marginado o instrumentalizado... es un riesgo para la sociedad.

Planteamos, en síntesis, que el principio que regula las actuales relaciones sociales entre sexos, esto es, la subordinación legal de un sexo al otro, es en sí misma errónea y, de paso, "uno de los principales impedimentos para la mejora del género humano; y que debería ser sustituido por el principio de perfecta igualdad entre ambos, sin admitir poder o privilegio en uno, ni inferioridad en el otro" (Stuart Mill, 2010, p. 29).

En su lugar, el llamado es a intentar re-sentipensar (Fals Borda, 2009) cuál es, o cuáles son, los proyectos educativos que realmente serían adecuados a nuestro territorio: descentralizarnos de neoliberalismo, cambiar la forma de relacionarnos y desescolarizarnos son parte de las ideas que colocamos a la discusión para pensar a futuro cómo avanzar hacia una educación no sexista: contra la cultura de la violación, contra el antropocentrismo, por espacios no determinados por roles de género, por una educación laica que permita la reflexión sobre derechos sexuales y reproductivos, revisiones curriculares (no-sexistas), formación inicial en igualdad de género, perfiles de egreso que conversen sobre género $\mathrm{y}$, finalmente, hacer interseccionalidad con otras formas de opresiones propias del actual sistema patriarcal, como la vulnerabilidad social, la búsqueda de salud digna, vivienda, territorio, sustentabilidad ecológica, autonomía de los pueblos, entre muchos otros y urgentes avances necesarios para transitar al küme möngen, esta vez mirando(nos) rumbo al sur desde el sur.

\section{REFERENCIAS BIBLIOGRÁFICAS}

Acuña, M. y Montecino, S. (2014). La otra reforma: el "No Sexismo" como clave cultural del cambio en el sistema educacional. Revista Anales. Séptima Serie, 7(1), 109-120. Recuperado de https:// revistas.uchile.cl/index.php/ANUC/article/view/35890/37538

Aguilar, P. (2015) Estrategias de cortesía verbal utilizadas en debates semipautados de jóvenes y adultos mayores de Santiago de Chile. Revista Lenguaje. Escuela de Ciencias del Lenguaje, 43(1), 111-136. Recuperado de http://www.scielo.org.co/pdf/leng/v43n1/v43n1a06.pdf

Aguilera, P. (17 de mayo de 2018). A un mes de la toma de la UACh: Todo lo que necesitas saber sobre las movilizaciones feministas. El Desconcierto. Recuperado de http://www. eldesconcierto.cl/2018/05/17/a-un-mes-de-la-toma-de-la-uach-todo-lo-que-necesitas-sabersobre-las-movilizaciones-feministas/

Arcos, E., Molina I., Trumper, R., Larrañaga, L., del Río, M., Tomic, P., Guerra, D., Uarac, M. y Szmuleviwcz, P. (2006). Estudio de perspectiva de género en estudiantes y docentes de la Universidad Austral de Chile. Estudios Pedagógicos, 32(2), 27-45.

Arriagada, N. (2016). Identidad y subjetivación política en el Movimiento por la salud digna en Chiloé. Revista Polis, 15(44), 263-287. Recuperado de https://scielo.conicyt.cl/scielo.php?script=sci_ 
abstract\&pid=S0718-65682016000200012\&lng=es\&nrm=iso .

Assaél, J., Acuña, F., Contreras, P. y Corbalán, F. (2014). Transformaciones en la cultura escolar en el marco de la implementación de políticas de accountability en Chile. Un estudio etnográfico en dos escuelas clasificadas en recuperación. Estudios Pedagógicos, 40(2), 7-26. Recuperado de http://dx.doi.org/10.4067/S0718-07052014000300001

Austin, J. L. (1962). Cómo hacer cosas con palabras. Barcelona: Paidós Ibérica.

Bauman, Z. (2007). Los retos de la educación en la modernidad líquida. Barcelona: Gedisa Editor.

Bauman, Z. (2012). Esto no es un diario. Barcelona: Paidós.

Bellei, C.; Poblete, X.; Sepúlveda, P.; Orellana, V. y Abarca, G. (2012). Situación educativa de América Latina y el Caribe: Hacia la educación para todos 2015. Documento de trabajo $N^{\circ} 7$. Centro de Investigación Avanzada en Educación CIAE: Santiago, Chile. Recuperado de http:// www.ciae.uchile.cl/index.php?page=view_publicaciones\&id_publicaciones $=357 \&$ langSite $=e s$

Bowman, N. (2010). College diversity experiences and cognitive development: a meta-analysis. Estados Unidos: Review of Educational Research.

Bowman, N. (2011). Promoting participation in a diverse democracy: a meta-analysis of college diversity experiences and civic engagement. Estados Unidos: Review of Educational Research.

Bowman, N. \& Brandenberger, J. (2012). Experiencing the unexpected: Toward a model of college diversity experiences and attitude change. Review of Higher Education, 35(2), 179-205. Recuperado de https://www.washington.edu/omad/files/2011/01/Bowman-Brandenberger.pdf

Butler, J. (2015). Cuerpos aliados y lucha política. Hacia una teoría performativa de la asamblea. Ciudad Autónoma de Buenos Aires: Paidós.

Butler, J. (2018). El género en disputa. El feminismo y la subversión de identidad. España: Paidós Estudio 168.

Dussel, E. (2007). Materiales para una política de la liberación. Madrid: Plaza y Valdés.

Escobar, A. (2016). Autonomía y Diseño. La realización de lo comunal. Popayán: Editorial del Cauca.

Espinosa, Y., Gómez, D. y Ochoa, K. (2014). Tejiendo de otro modo: Feminismo, epistemología y apuestas descoloniales en Abya Yala. Popayán: Editorial Universidad del Cauca.

Fals Borda, O. (2009). Una sociología sentipensante para América Latina. Antología. Buenos Aires: CLACSO.

Fernández, J. (2009). El amor a Žižek. Un acercamiento al amor desde la noción de Slavoj Žižek. Sociogénesis, Revista Electrónica de Sociología, (2), 2-14. Recuperado de: https://cdigital. uv.mx/bitstream/handle/123456789/9619/ar2_jul-dic2009.pdf?sequence=2\&isAllowed=y

Foucault, M. (1992). El orden del discurso. Lección inaugural en el Collège de France pronunciada el 2 de diciembre de 1970. Buenos Aires: Tusquets Editores.

Fuentes, H. (2013). Slavoj Žižek subtitulado al español [video] Recuperado de: https://www.youtube. $\mathrm{com} / \mathrm{watch} ? \mathrm{v}=\mathrm{oR} 1 \mathrm{nF} \_\mathrm{w} \_\mathrm{q} 7 \mathrm{w} \&$ feature=youtu.be

González, C. (2017). Identidad. Rutas de la identidad trazadas por la ideología. La trama de la comunicación, 21(1), 15-27. Recuperado de: http://www.scielo.org.ar/scielo.php?script=sci_ arttext\&pid=S1668-56282017000100001\&lng=es\&tlng=es

Illich, I. (2011). La sociedad desescolarizada. Buenos Aires, Argentina: Editorial Godot.

Lakoff, R. (1990). Talking power, the politics of language. Estados Unidos: Editorial Basic Books.

Lillo, D. (2016). Patriarcado, educación, literatura. El discurso femenino omitido en los Programas de estudio de Lenguaje y Comunicación de enseñanza media. En del Valle (Ed.), Educación No Sexista. Hacia una Real Transformación (pp. 25-36). Santiago: Red Chilena contra la Violencia hacia las Mujeres.

Llorente, M. (1996). Organizadores de la conversación. Operadores discursivos del español. España: Publicaciones Universidad Pontificia Salamanca.

Márquez, M. (2013). Género gramatical y discurso sexista. Madrid. Editorial síntesis.

Naciones Unidas, CEPAL, Comisión económica para América latina y el Caribe (2010). Panorama social de América Latina. Santiago de Chile. 
OCDE (2009). Revisión de Políticas Nacionales de Educación. La Educación Superior en Chile. OCDE, Banco Mundial. Recuperado de http://www.oecd-ilibrary.org/la-educacion-superior-enchile_5ksntst3t7hd.pdf

Pérez, V. (2011). Discurso en inauguración de año académico 2011. Recuperado de http://www. uchile.cl/

PNUD (informe) (2009) y (2004). Informe de desarrollo humano en Chile. Recuperado de http:// www.pnud.cl/prensa/4.asp\#Informes_de_Desarrollo_Humano_en_Chile_

Rodríguez, M. (2018). Formas y medios de comunicación usados por el movimiento estudiantil chileno en los años 2006 y 2011. Revista Latina de Sociología (RELASO), 8(1), 82-101. DOI:https://doi.org/10.17979/relaso.2018.8.1.3214

Scott, J. (2008). Género e Historia. México D. F. México. Fondo de Cultura Económica. Universidad Autónoma de la Ciudad de México.

Searle, J. (1969). Actos de habla. Madrid: Ediciones Cátedra.

Sebastián, J. (2007) Conocimiento, cooperación y desarrollo. Centro de Información y Documentación Científica (CINDOC), CSIC, España. Revista CTS, 8, (3), 195-208.

Solimano y Torche (2008) La distribución del ingreso en Chile 1987-2006: análisis y consideraciones de política. Banco Central de Chile. Santiago de Chile.

Sousa, B. (2010). Descolonizar el saber, reinventar el poder. Montevideo: Ediciones Trilce.

Stolcke, V. (1996). Antropología del género. El cómo y el porqué de las mujeres. En J. Prat y A. Martínez (Eds.), Ensayos de Antropología cultural (pp. 335 -343). Barcelona: Ariel.

Stuart Mill, J. (2010). El sometimiento de la mujer. Madrid: Sociología, Alianza editorial.

Valle del, J. (21 de agosto de 2018). Política de la incomodidad. Anuario de glotopolítica. Notas sobre gramática y lenguaje inclusivo. Recuperado de https://glotopolitica.com/2018/08/21/lapolitica-de-la-incomodidad/

Žižek, S. (2011). En defensa de las causas perdidas. Madrid: Ediciones Akal S.A.

Žižek, S. (2012). No actúes. iSolo piensa! [video]. Recuperado de https://www.youtube.com/ watch? $=\mathrm{k} 2 \mathrm{x} 8 \mathrm{TC}-\mathrm{zXio}$ 
